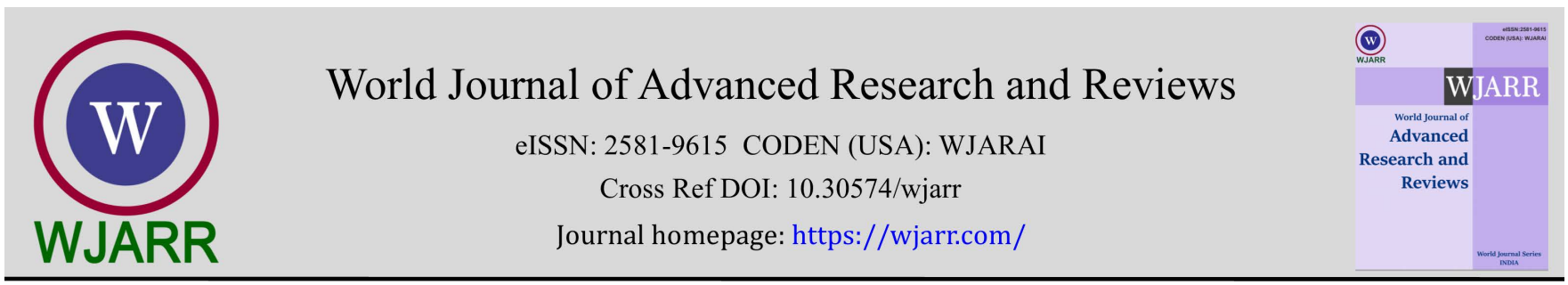

(REVIEW ARTICLE)

Check for updates

\title{
Smoking as an environmental hazard to the periodontal and peri-implant tissues: A brief review
}

\author{
Avigdor Klinger * \\ Department of Periodontology, Hadassah Medical Center, Faculty of Dental Medicine, Hebrew University of Jerusalem \\ P.O.Box 12272, Jerusalem 91120, Israel.
}

World Journal of Advanced Research and Reviews, 2021, 12(03), 340-348

Publication history: Received on 15 October 2021; revised on 14 December 2021; accepted on 16 December 2021

Article DOI: https://doi.org/10.30574/wjarr.2021.12.3.0578

\begin{abstract}
While dental plaque is considered the etiological factor for the development of periodontal and peri-implant diseases, many studies from recent years point to smoking as the most significant environmental factor contributing to disease severity. This effect is evident at the epidemiological level as well as on our understanding of the biological mechanisms involved. The present review presents abundant scientific evidence showing that smoking negatively affects the local blood supply, interferes with the reaction of the immune system to bacterial insult, is toxic to gingival and periodontal ligament cells, impedes the response of the periodontal attachment apparatus to treatment, and is linked to dental implant failure.

Over the past 30 years, more than 200 million people have died as a result of smoking tobacco use. There are more than 1 billion current smokers worldwide and these numbers are likely to increase over the coming years. And yet, the effect of smoking on periodontal and peri-implant health has been a controversial issue. It was argued, that it is difficult to prove such an effect due to poor adherence of smokers to oral hygiene, which creates a confounding factor inseparable from the effect of the smoking itself. Unfortunately, even some of the more recent publications cast doubt as for the importance of smoking cessation on peri-implant health, as a prerequisite for a successful treatment.
\end{abstract}

The aim of the present review was to question the validity of these reports by presenting multiple evidence to support the quiet widely accepted common knowledge that is the numerous hazards to the oral biology which are the result of a heavy and prolonged smoking habit.

Keywords: Periodontitis; Periodontal-therapy; Peri-Implantitis; Implant-Success; Smoking;

\section{Epidemiological and Clinical Observations in Smokers}

The rate of smokers decreases with age and is about 35\% at age 35 and $12 \%$ at age 75 [1] . A recent study found that the rate of current smokers in the US is $5 \%$ and about $60 \%$ for former smokers. The incidence of periodontal disease is twice as high in smokers (25\%) as compared to non-smokers (13\%) [2]. In 28\% of smokers (S), at least one site was found with loss of periodontal attachment (CAL) as compared to only $9 \%$ among non-smokers (NS). There is an increased risk (Odds Ratio $(\mathrm{OR})=3$ ) for periodontal disease in subjects who smoke half a pack per day, while those who stopped smoking within the last two years are still with a similar risk. Moreover, OR of 6 was found between smoking a pack and a half a day and periodontal disease. The authors of the research state that smoking might explain about half of all periodontitis cases [3] . Advanced periodontal disease was found in 15\% among S, compared to just 3.5\% among NS [4] . In a longitudinal study in Sweden, only 9\% of examined patients without periodontitis where smokers in

\footnotetext{
${ }^{*}$ Corresponding author: Avigdor Klinger; E-mail:Avigdork@ekmd.huji.ac.il

Department of Periodontology, Hadassah Medical Center, Faculty of Dental Medicine, Hebrew University of Jerusalem P.O.Box 12272, Jerusalem 91120, Israel. 
comparison to $38 \%$ in the NS group. In that study, an increased risk of OR=20 was found for smoking and periodontitis [5]. A higher percentage of smokers was found among advanced periodontitis patients (58\%) as compared with those who were diagnosed with an initial disease (10\%). Smokers have an OR of 12 to be diagnosed with advanced periodontitis compared to the mild form [6]. More smokers were found with rapidly progressing than with adult periodontitis [7]. In S, there is a constant increase in clinical attachment level (CAL), measurable pocket depth (PD) and number of missing teeth. At a younger age, the difference is mainly in pocket depth (PD) and CAL. In the older age, this difference is mainly in CAL and missing teeth.

The relationship between age and smoking is additive but not synergistic. For S under age 40 the same CAL was found as for NS over age 50. Each year of age adds $0.02 \mathrm{~mm}$ to CAL while every pack year adds $0.01 \mathrm{~mm}$ [8, 9]. A longitudinal study found that CAL is three times higher in smokers. There is a correlation between cotinine level and CAL. A five-fold increased risk was found for advanced CAL in smokers [10]. In a ten-year longitudinal study, Bergstrom and colleagues found, that there was a decrease in height of the alveolar ridge in S but not in NS is spite of the periodontal treatment provided. No difference was found between S and EX-smokers (ES). There is a significant impact for duration and the amount of smoking [11]. Smokers have more angular bone resorption lesions. Bone loss over two standard deviations (SD) from average exists only in smokers. Smoking has an effect on bone resorption and also on formation of angular bony lesions. In about $74 \%$ of the young patients and $100 \%$ of adults who smoke, bone resorption is about 2 SD above the mean [12]. Rate of CAL as expressed in recessions is twice as high, mostly on the buccal side [13].

Smoking, is also associated with a greater tooth loss [14]. In a ten-year longitudinal study, the difference was reflected in increased number of teeth lost in smokers (4 teeth) compared to non-smokers (2.5 teeth), but no difference in CAL or PD. This difference is not accompanied by a parallel difference at the level of cotinine in the crevicular fluid [15]. Smokers have about 16 teeth on average, compared to 23 in NS [13]. From a group of patients with Generalized-Early Onset Periodontitis, about 70\% were smokers vs. only 40\% with Localized - Early Onset Periodontitis [16]. At age 75, about $41 \%$ of smokers are toothless compared to only $35 \%$ of NS. The difference in the number of missing teeth between non-smokers and smokers increased from a younger age (0.6) to adults (5.8). The difference in reduction of the level of periodontal attachment also increases from a younger age (0.4) to adults (1.3) [1]. Among the few studies, with conflicting conclusions is the one by Bostrom et al., who argued that there is no difference in clinical indices between $\mathrm{S}$ and NS [17]. Also, no correlation was found between sites with CAL and pack years in the Chinese population [18].

\section{Plaque levels and the microbiological profile}

As for quantity and composition of biofilm, according to some studies, it can be concluded that there is no difference between S and NS [1, 8, 10,17]. In contrast, Gunsolley and colleagues argue that these are higher in smokers [13]. Eighty six percent of surfaces were found with plaque in S in comparison to 65\% in NS or in former smokers (ES). Other investigators suggest that the effect of smoking is thus reversible [19] and there is more plaque and sites with PD $>4$ $\mathrm{mm}$ in S after age 40 [12]. In S there is an 11-fold probability for the presence of periodontopathic bacteria compared to NS [20]. Levels of Bacteroides forsythus are higher in S, especially in pockets of medium depth [21]. In a sample of S without periodontal disease, at least one periodontopathogen was found in $30 \%$ of cases compared to $0.5 \%$ in NS. An OR of 18 was found between smoking and the presence of periodontopathogens [22] and OR $=9$ for the presence of positive N-benzoyl-dL-arginine-2-napthylamide (BANA) bacteria. Also, there is an OR = 5 between former smokers and the presence of positive BANA bacteria [23] and OR = 1.5 between smoking and presence B. forsythus [4] and elevated levels of Treponema denticola in pockets of S [24]. An opposing view but in minority, stands the opinion of Darby et al., who state that there is no microbiological difference between S and NS [25].

\section{Local blood supply and gingival inflammation}

Lower oxygen pressure in the gingival tissues was found in smokers, although there is no decrease in saturation of oxygen in their blood hemoglobin. A positive correlation exists in nonsmokers between PD and $\mathrm{PO}_{2}$. This correlation does not exist in smokers. In healthy gingiva the oxygen pressure is higher in nonsmokers [26]. No difference in blood flow between S and NS in short term reaction to controlled smoking [27] was observed. However, following local infiltration of anesthetic, a 25\% higher resistance is measured in S compared to NS (28). Most of the studies, point to lower bleeding index in S $[2,8,17,21]$. Also, bleeding index following probing is lower in S [9, 25]. Bleeding index at the gingival margin is only $15 \%$ in S compared to $30 \%$ in NS. Bleeding at the pocket base was found to be $27 \%$ in S as compared to $44 \%$ in NS. The transition from a healthy state to gingivitis is faster in NS [29]. Gingival index is lower in S in spite of a similar disease severity as in NS [30]. Bleeding index is $36 \%$ in NS compared to $14 \%$ in S. Moreover, smokers possess one more tooth with furcation involvement as compared with NS [31]. In contrast, Kinane et al. suggest that no difference exists between S and NS in bleeding after probing [1,12,32]. However, more bleeding after probing and less 
reduction in pocket depth was found in S following therapy [33, 34, 35]. Only one study showed higher gingival index and crevicular fluid in $\mathrm{S}$ without periodontal disease [36].

\section{Immune system}

A decrease in $\operatorname{IgG}_{2}$ level was found in smokers with Generalized-Early Onset Periodontitis [37, 38, 39]. According to Persson and colleagues, in S similar levels of Lactoferrin and elastase, but lower levels of antitrypsin and lower concentration of macroglobulin compared to NS in medium and deep pockets were found. Since these are antibacterial enzymes produced by polymorphonuclear cells, this difference may reflect a diminished responsiveness of the immune system in smokers [40]. Moreover, smoking has a negative effect on the PMN count, antitrypsin and lgG levels, but not on the formation of free radicals by polymorphonuclear cells [41]. In vitro, nicotine combined with lipopolysaccharide of $P$. gingivalis, increased $\mathrm{PGE}_{2}$ but not Il- $1 \beta$ secretion by peripheral mononuclear cells. The combination between them has an additive effect resulting in a higher level of $\mathrm{PGE}_{2}$ than each substance alone [42]. TNF- $\alpha$ levels were 3 times higher in S as compared to ES, and five times higher in ES versus NS. No correlation was found between PD and TNF level, but TNF- $\alpha$ level was higher in smokers [17]. In contrast, no difference was found between $S$ and NS in $\mathrm{PGE}_{2}$ levels. In patients with periodontal disease, higher levels can be found than in patients with gingivitis [43]. There is no difference in lg, Il1$\beta$ and II1- $\alpha$ between NS and S. An OR=7 was found between smoking and advanced periodontal disease, but only 1.7 combined with smoking and a positive genotype of Il-1 $\beta$ and advanced disease [44].

\section{Toxicity}

Arecoline and nicotine synergistically act as inhibitors of proliferation of fibroblast from the PDL and diminish protein synthesis [45]. Nicotine inhibits proliferation, chemotaxis, and adherence of fibroblasts from the PDL in a manner which is concentration dependent [46]. A synergism exists between bacterial endotoxin and nicotine which is formed during smoking. For example, LPS alone at a sub-clinical concentration does not kill fibroblasts, but only in combination with nicotine [47]. In the tissues there are more free radicals in S. Injection of nicotine to animals in combination with ligature placement promotes plaque formation and bone resorption [48]. Smoking inhibits fibroblasts adherence, ALP activity and chemotaxis of PDL cells [46]. It has been found that nicotine interferes with the intercellular adherence capabilities ( $\beta$-integrin) of fibroblasts [49]. In summary, smoking has inhibitory influence on positive processes but does not interfere with negative ones that promote the propagation of periodontal diseases [50].

\section{Response to Treatment}

Clinical reduction in pocket depth was found to be smaller in $\mathrm{S}$ after phase 1 therapy [51]. Following full mouth disinfection, in which treatment is performed within 24 hours, more gain is obtained in periodontal attachment as compared to the standard protocol (quadrants technique). The difference between these protocols is greater in NS [52]. Repeated scaling and planing of roots in smoking patients with recurrent periodontal disease does not contribute to clinical improvement [53]. In S, there is less improvement in periodontal attachment ( $1.8 \mathrm{~mm})$, than in NS ( $2.8 \mathrm{~mm})$, in pocket depths over $6 \mathrm{~mm}$. In S, there is 1.4 times higher probability not to improve their PD to below $3.0 \mathrm{~mm}$ and CAL more than $2.0 \mathrm{~mm}$ [54]. The mean reduction of PD is $2.5 \mathrm{~mm}$ in NS compared to $1.9 \mathrm{~mm}$ in S after initial periodontal treatment. In $\mathrm{S}$ there is some reduction in PD and an improvement in periodontal attachment, but not in furcation lesions. Furthermore, they have a greater deterioration during maintenance [55]. After removing calculus and root planing there is less benefit in $\mathrm{S}$ in pocket depth changes and attachment levels [56]. Response to surgical treatment and expected change in bone height after five years is 1\% in S compared to 7\% in NS. There was however no difference between S and NS groups before treatment [17]. In S, there is no correlation between initial condition and posttreatment improvement. The lack of correlation is more pronounced in deep pockets. The changes were observed mostly in PD, but not in CAL or bleeding during probe examination [31]. Percentage of sites with improved attachment after initial treatment is higher in NS (14\%) compared to S (9\%). There was less loss of CAL in non-smokers and no bone loss over the study period [57]. About $11 \%$ of NS patients required postoperative surgical initial treatment vs. 42 $\%$ among S [58].

Microbiologically, levels of B. forsythus and P. gingivalis in S were higher after periodontal treatment compared to NS [59]. The reduction in the Spirochete rate was smaller in S after removal of calculus and planing of roots [51]. There is no decrease in T. denticola, $B$.forsythus and P.gingivalis levels after initial treatment in S [60]. Moreover, no decreased PD and CAL were observed. A smaller decrease was measured in PD in S about six months after initial treatment and more bleeding found on examination with a probe and the presence of the bacterium Aggregatibacter actinomycetemcomitans [32]. 
Following guided tissue regeneration and gingival grafting, $100 \%$ of cases were found with membrane exposure in S compared to $50 \%$ in NS. Also, in cases where the membrane has been exposed there was a decrease of $50 \%$ in periodontal attachment gain. In $S$ more recession developed following treatment [61, 62] with no significant gain in periodontal attachment using a membrane compared with the control [63]. Using a resorbable Guidor membrane, there is twice as much bone filling in the intra bony lesions in NS [64]. After treatment, recession was measured $0.1 \mathrm{~mm}$ in NS compared to $1.3 \mathrm{~mm}$ in S. Resorption of the alveolar crest was close to $0 \mathrm{~mm}$ in NS compared to $0.7 \mathrm{~mm}$ in S. Resolution of horizontal furcation, was about $2.8 \mathrm{~mm}$ in NS compared to $1.5 \mathrm{~mm}$ in S [65]. There was a non-resorbable PTFE membrane exposure at a higher rate in S. Parallelly, reduction of recession was smaller in S (2.5 mm, $57 \%$ coverage) compared to NS (3.6 mm, 78\% coverage) [61]. Thus, smoking negatively affects mucogingival root coverage procedures [66].

\section{Dental Implant Failure}

From the first publications reporting the consequences of smoking on the success of implants, Bain \& Moy's research stands out encompassing more than 2,000 implants over six years. The authors of the article conclude that the rate of failure in smokers, is more than double (11\%) in comparison to non-smokers (4.7\%) [67]. These differences between groups were expressed in all areas of mouth except in the posterior mandible $[67,68]$. Smoking cessation (ES), improves success rates compared to $\mathrm{S}$, without difference between the ES group and the non-smoking group [69]. Around implants in smokers, there are more sites with mucositis, deeper pockets and more advanced bone resorption compared with implants in non-smokers [70]. Smokers are 2.5 times more likely to implant failure within 4-6.5 years following actual placement and augmentation with bone mineral [71]. At follow-up of 60 months in implants inserted into the maxillary sinus area after augmentation, a success rate of $82 \%$ was recorded in NS compared to only $67 \%$ in smokers $[72,73]$. A recently published article emphasizes the following factors that were identified as risk indicators for periimplantitis: smoking (OR $=3.59 ;)$, moderate/severe periodontitis $(\mathrm{OR}=2.77),<16$ remaining teeth $(\mathrm{OR}=2.23)$, plaque $(\mathrm{OR}=3.49)$, implant malposition (too vestibular implant placement: $\mathrm{OR}=2.85)$, implant brand $(\mathrm{OR}=4.41)$, restoration type (bridge vs. single crown: $O R=2.47$ ), and trauma as reason of tooth loss (vs. caries: $O R=6.51$ ) [74].

\section{Peri-implant complications in Patients with a History of Periodontitis and Supportive Periodontal Therapy}

Abundant data is available showing higher rates of peri-implant disease in patients diagnosed with periodontitis. For example, Hardt et al. [75] have found that after 5 years, 24\% of the patients without periodontal disease lose above 2 $\mathrm{mm}$ of bone surrounding the implants. In comparison, this figure is more than $60 \%$ for patients diagnosed with periodontitis. Karoussis et al. [76] shows that while implant failure rate in patients losing teeth from non-periodontal reasons after 10 years of follow-up was only 4\%, in patients losing teeth due to poor periodontal prognoses, this figure is much higher, at about $10 \%$.

A greater deterioration in periodontal indices were found in S [55] during supportive periodontal therapy. Twelve months following periodontal treatment, 3-fold more CAL loss was noted along with recession in S. There were twice as many smoking patients with bone loss after taking in account confounding factors such as education and income. Positive correlations were found between CAL and blood cotinine level, and between B. forsythus levels and PD in S [11]. Smoking was a significant, negative predictor for supportive periodontal treatment duration [77]. Qualitatively, significantly less smokers returned for SPT than non-smokers or former smokers [78].

\section{Conclusion}

In a special edition of the Journal of Clinical Periodontology published recently, Berglundh et al. stated that data identifying smoking as potential risk indicators for peri-implantitis are inconclusive [79]. Another study, suggested that Periodontitis and Periimplantitis are two distinct diseases [80]. Combining these two notions together might create a dangerous impression for the readers that maybe, a smoking patient is at no greater risk for implant failure just because he smokes. Moreover, since abundant evidence exists as to the higher incidence of periimplantitis in periodontally susceptible patients, these two diseases cannot be truly separated for smokers.

So, while dental plaque is considered the etiological factor for the development of periodontal and peri-implant diseases, many studies from recent years point to smoking as the most significant environmental factor contributing to disease severity. This effect is evident at the epidemiological level as well as the biological mechanisms involved. The abundant data presented here, unequivocally support the view that smoking negatively affects the local blood supply and gingival 
inflammation, interferes with the reaction of the immune system, is toxic to gingival and periodontal ligament cells, impedes the response of the periodontal attachment apparatus to treatment, and is linked to dental implant failure.

Therefore, patients seeking our treatment should be informed of the dangers posed by their smoking and urged to get professional help for smoking cessation prior to giving full consent to being treated. The dental professionals hold a key position as health providers not only as far as oral health is concerned, but as part of a global effort to combat this harmful addiction [81].

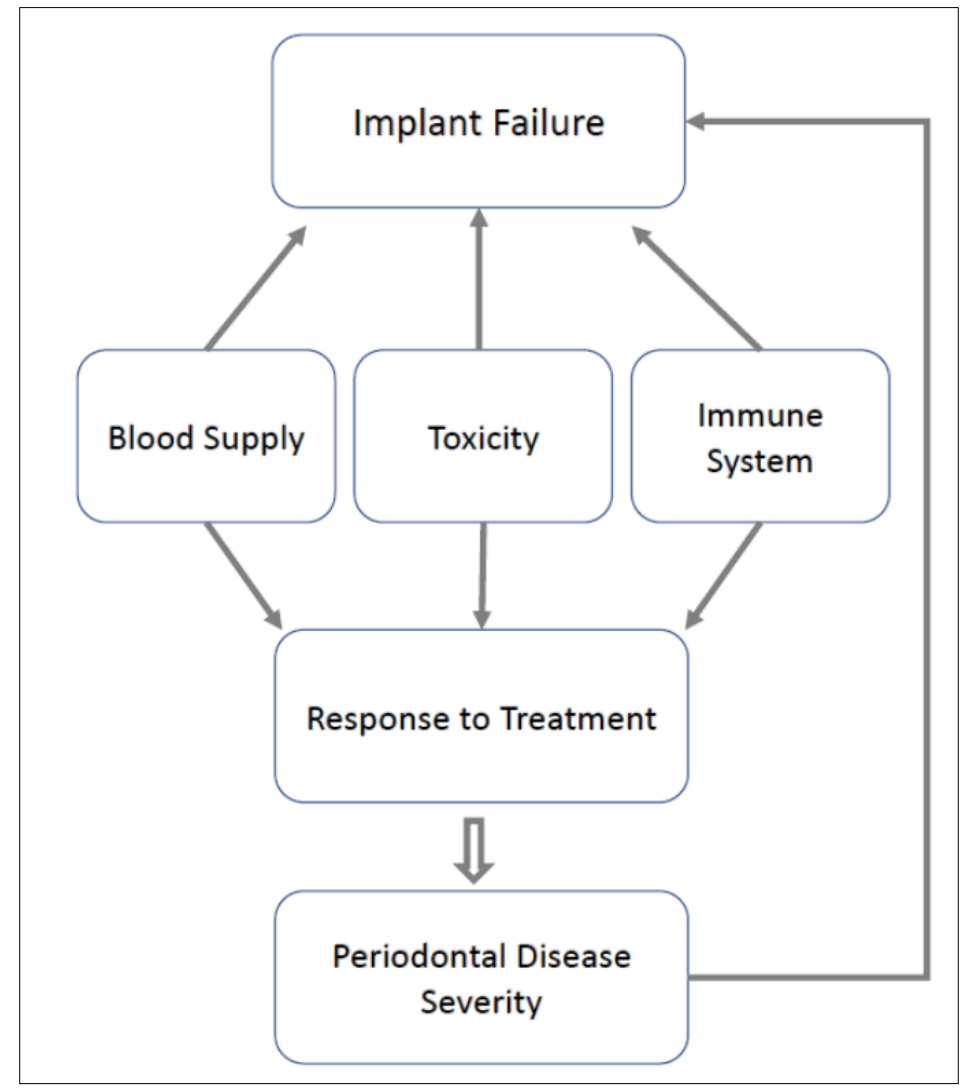

Figure 1 Diagram representing the effect patterns smoking has on the periodontal and peri-implant health

\section{Compliance with ethical standards}

\section{Acknowledgements}

This review was written with guidance by my mentors in the post-graduate program in Periodontology

\section{Disclosure of conflict of interest}

The corresponding author states that no conflict of interest was involved in writing this paper

\section{References}

[1] Axelsson P, Paulander J, Lindhe J. Relationship between smoking and dental status in 35-, 50-, 65- and 75-yearold individuals. J Clin Periodontol. 1998; 25: 97-3-05.

[2] Albandar JM, Streckfus CF, Adesanya MA, et al. Cigar, pipe, and cigarette smoking as risk factors for periodontal disease and tooth loss. J Periodontol. 2000; 71: 1874-1881.

[3] Tomar SL, Asma S. Smoking-attributable periodontitis in the United States: findings from NHANES Ill. National Health and Nutrition Examination Survey. J Periodontol. 2000; 71: 743-751. 
[4] Zambon JJ, Grossi SG, Machtei EE, et al. Cigarette smoking increases the risk for subgingival infection with periodontal pathogens. J Periodontol. 1996; 67(10): 1050-1054.

[5] Norderyd 0, Hugoson A, Grusovin G. Risk of severe periodontal disease in a Swedish adult population. A longitudinal study. J Clin Periodontol. 1999; 26: 608--615.

[6] Kornman KS, Crane A, Wang HY, et al. The interleukin-1 genotype as a severity factor in adult periodontal disease. J Clin Periodontol. 1997; 24: 72-77.

[7] Monteiro da Salva AM, Newman HN, Oakley DA, et al. Psychological factors, dental plaque levels and smoking in periodontitis patients. J Clin Periodontol. 1998; 25: 517-523.

[8] Bostrom L, Bergstrom J, Dahlen G, et al. Smoking and subgingival microflora in periodontal disease. J Clin Periodontol. 2001; 28: 212-219.

[9] Haffajee AD, Socransky SS. Relationship of cigarette smoking to attachment level profiles. J Clin Periodontol. 2001; 28: 283-295.

[10] Machtei EE, Dunford A, Hausmann E, et al. Longitudinal study of prognostic factors in established periodontitis patients. J Clin Periodontol. 1997; 24: 102-109.

[11] Bergstrom J, Eliassen S, Dock J. A 10-year prospective study of tobacco smoking and periodontal health. J Periodontol. 2000; 71: 1338-1347.

[12] Persson RE, Hollender LG, Persson GR. Assessment of alveolar bone levels from intraoral radiographs in subjects between ages 15 and 94 years seeking dental care. J Clin Periodontol. 1998; 25: 647-654.

[13] Gunsolley JC, Quinn SM, Tew J, et al. The effect of smoking on individuals with minimal periodontal destruction. J Periodontol. 1998; 69: 165-170.

[14] McGuire MK, Nunn ME. Prognosis versus actual outcome. Ill. The effectiveness of clinical parameters in accurately predicting tooth survival. J Periodontol. 1996; 67: 666-674.

[15] Chen X, Wolff. L, Aeppli, D et al. Cigarette smoking salivary/gingival crevicular fluid cotinine and periodontal status. A 10 year longitudinal study. J Clin Periodontol. 2001; 28: 331- 339.

[16] Mullally BH, Breen B, Linden GJ. Smoking and patterns of bone loss in early-onset periodontitis. J Periodontol. 1999; 70: 394-401.

[17] Bostrom L, Linder LE, Bergstrom J. Smoking and I 2 GCF levels of IL-1beta and IL-1ra in periodontal disease. J Clin Periodontol. 2000; 27: 250-255.

[18] Suda R, Cao C, Hasegawa K, et al. A 2-year observation of attachment loss in a rural Chinese I population. J Periodontal. 2000; 71: 1067-1072.

[19] Bergstrom J. Tobacco smoking and supragingival dental calculus. J Clin Periodontol 1999; 26: 541-547.

[20] Kazor C, Taylor GW, Loesche WJ. The prevalence of SANA-hydrolyzing periodontopathic bacteria in smokers. J Clin Periodontol. 1999; 26: 814-821.

[21] Bostrom L, Bergstrom J, Dahlen G, et al. Smoking and subgingival microflora in periodontal disease. J Clin Periodontol. 2001; 28: 212-219.

[22] Shiloah J, Patters MR, Waring MB. The prevalence of pathogenic periodontal microflora in healthy young adult smokers. J Periodontol. 2000; 71:562-567.

[23] Loesche WJ, Kazor CE, Taylor GW. The optimization of the SANA test as a screening instrument for gingivitis among subjects seeking dental treatment. J Clin Periodontol. 1997; 24: 718-726.

[24] Urneda M, Chen C, Bakker I, et al. Risk indicators for harboring periodontal pathogens. J Periodontol. 1998; 69: 1111-1118.

[25] Darby 18, Hodge PJ, Riggio MP, et al. Microbial comparison of smoker and non-smoker adult and early-onset periodontitis patients by polymerase chain reaction. J Clin Periodontol. 2000; 27: 417-424.

[26] Hanioka T, Tanaka M, Ojima M, et al. Oxygen sufficiency in the gingiva of smokers and non-smokers with periodontal disease. J Periodontol. 2000; 71: 1846-1851.

[27] Meekin TN, Wilson RF, Scott DA, et al. Laser Doppler flowmeter measurement of relative gingival and forehead skin blood flow in light and heavy smokers during and after smoking. J Clin Periodontol. 2000; 27: $236-242$. 
[28] Ketabi M, Hirsch RS. The effects of local anesthetic containing adrenaline on gingival blood flow in smokers and non-smokers. J Clin Periodontol. 1997; 24: 888-892.

[29] Lie MA, Timmerman MF, van der Velden U, et al. Evaluation of 2 methods to assess gingival bleeding in smokers and non-smokers in natural and experimental gingivitis. J Clin Periodontol. 1998; 25: 695-700.

[30] Ozmeric N, Bal B, Salos K, et al. The correlation of gingival crevicular fluid interleukin- $\alpha$ levels and periodontal status in localized juvenile periodontitis. J Periodontol. 1998; 69: 1299-1304.

[31] Mullally BH, Linden GJ. Molar furcation involvement associated with cigarette smoking in periodontal referrals. J Clin Periodontol. 1996; 23: 658-661.

[32] Kinane OF, Radvar M. The effect of smoking on mechanical and antimicrobial periodontal therapy. J Periodontol. 1997; 68: 467-472.

[33] Renvert S, Dahlen G, Wikstrom M. The clinical and microbiological effects of non-surgical periodontal therapy in smokers and non-smokers. J Clin Periodontol. 1998; 25: 153-157.

[34] Weyant RJ, Pearlstein ME, Churak AP, et al. The association between osteopenia and periodontal attachment loss in older women. J Periodontol. 1999; 70: 982-991.

[35] Payne JB, Reinhardt RA, Nummikoski PV, et al. The association of cigarette smoking with alveolar bone loss in postmenopausal females. J Clin Periodontol. 2000; 27: 658-664.

[36] Shiloah J, Patters MR, Waring MB. The prevalence of pathogenic periodontal microflora in healthy young adult smokers. J Periodontol. 2000; 71: 562-567.

[37] Tangada SD, Califano JV, Nakashima K, et al. The effect of smoking on serum lgG2 reactive with Actinobacillus actinomycetemcomitans in early-onset periodontitis patients. J Periodontol. 1997; 68: 842-850.

[38] Quinn SM, Zhang JB, Gunsolley JC, et al. The influence of smoking and race on adult periodontitis and serum lgG 2 levels. J Periodontol. 1998; 69: 171-177.

[39] Kremer BH, Loos BG, van der Velden U, et al. Peptostreptococcus micros smooth and rough genotypes in periodontitis and gingivitis. J Periodontol. 2000; 71: 209-218.

[40] Persson L, Bergstrom J, Ito $\mathrm{H}$, et al. Tobacco smoking and neutrophil activity in patients with periodontal disease. J Periodontol. 2001; 72: 90-95.

[41] Fredriksson Ml, Figueredo CM, Gustafsson A, et al. Effect of periodontitis and smoking on blood leukocytes and acute-phase proteins. J Periodontol. 1999; 70: 1355-1360.

[42] Bernzweig E, Payne JB, Reinhardt RA, et al. Nicotine and smokeless tobacco effects on gingival and periph eral blood mononuclear cells. J Clin Periodontol. 1998; 25: 246-252.

[43] Heasman PA, Lauffart BL, Preshaw PM. Crevicular fluid prostaglandin $E_{2}$ levels in periodontitis-resistant and periodontitis-susceptible adults. J Clin Periodontol. 1998; 25: 1003-1007.

[44] McDavitt MJ, Wang HY, Knobelman C, et al. Interleukin-1 genetic association with periodontitis in clinical practice. J Periodontol. 2000; 71: 156-163.

[45] Chang YC, Lii CK, Tai KW, et al. Adverse effects of arecoline and nicotine on human periodontal ligament fibroblasts in-vitro. J Clin Periodontol. 2001; 28: 277-282.

[46] Giannopoulou C, Geinoz A, Cimasoni G. Effects of nicotine on periodontal ligament fibroblasts in-vitro. J Clin Periodontol. 1999; 26: 49-55.

[47] Sayers NM, James JA, Drucker DB, et al. Possible potentiation of toxins from Prevotella intermedia, Prevotela nigrescens, and Porphyromonas gingivalis by cotinine. J Periodontol. 1999; 70: 1269-1275.

[48] Nociti FH Jr, Nogueira-Filho GR, Primo MT, et al. The influence of nicotine on the bone loss rate in ligature-induced periodontitis. A histometric study in rats. J Periodontol. 2000; 71: 1460-1464.

[49] Austin GW, Cuenin MF, Hokett SD, et al. Effect of nicotine on fibroblast beta 1 integrin expression and distribution in-vitro. J Periodontol. 2001; 72: 438-444.

[50] Faddy MJ, Cullinan MP, Palmer JE, et al. Anti-dependence modeling in a longitudinal study of periodontal disease: the effect of age, gender, and smoking status. J Periodontol. 2000; 71: 454-459. 
[51] Palmer RM, Matthews JP, Wilson RF. Non-surgical periodontal treatment with and without adjunctive metronidazole in smokers and non-smokers. J Clin Periodontol. 1999; 26: 158-163.

[52] Mongardini C, van Steenberghe D, Dekeyser C, et al. One stage full- versus partial-mouth disinfection in the treatment of chronic adult or generalized early-onset periodontitis. I. Long-term clinical observations. J Periodontol. 1999; 70: 632-645.

[53] Soder B, Nedlich U, Jin W. Longitudinal effect of non-surgical treatment and systemic metronidazole for 1 week in smokers and non-smokers with refractory periodontitis: a 5-year study. J Periodontol. 1999; 70: $761-771$.

[54] Scabbia A, Cho KS, Sigurdsson TJ, et al. Cigarette consumption and response to periodontal therapy. J Periodontol. $2001 ; 72: 43-49$.

[55] Kaldhal WB, Johnson GK, Patil KD, et al. Levels of cigarette consumption and response to periodontal therapy. J Periodontol. 1996; 67: 675-681.

[56] Ryder MI, Pons B, Adams D et al. Effects of smoking on local delivery of controlled-release doxycycline as compared to scaling and root planing. J Clin Periodontol. 1999; 26:683-691.

[57] Hausmann E, Schmidt M, Grossi SG, et al. Radiographic and clinical responses to periodontal therapy. J Periodontol. 1998; 69: 590-595.

[58] Papantonopoulos GH. Smoking influences decision making in periodontal therapy: a retrospective clinical study. J Periodontol. 1999; 70: 1166-1173.

[59] Grossi SG, Zambon J, Machtei EE, et al. Effects of smoking and smoking cessation on healing after mechanical periodontal therapy. J Am Dent Assoc. 1997; 128:599-607.

[60] Haffajee AD, Cugini MA, Dibart S, et al. Clinical and microbiological features of subjects with adult periodontitis who responded poorly to scaling and root planing. J Clin Periodontol. 1997; 24: 767-776.

[61] Trombelli L, Scabbia A. Healing response of gingival recession defects following guided tissue regeneration procedures in smokers and non-smokers. J Clin Periodontol. 1997; 24: 529-533.

[62] Caffesse RG, Mota LF, Quinones CR, et al. Clinical comparison of resorbable and non-resorbable barriers for guided periodontal tissue regeneration. J Clin Periodontol. 1997; 24: 747-752.

[63] Mayfield L, Soderholm G, Hallstrom H, et al. Guided tissue regeneration for the treatment of intraosseous defects using absorbable membrane. A controlled clinical study. J Clin Periodontol. 1998; 25: 585-595.

[64] Luepke PG, Mellonig JT, Brunsvold MA. A clinical evaluation of a bioresorbable barrier with and without decalcified freeze-dried bone allograft in the treatment of molar furcations. J Clin Periodontol. 1997; 24: 440446.

[65] Scott TA, Towle HJ, Assad DA, et al. Comparison of bioadsorbable laminar bone membrane and non-resorbable e-PTFE membrane in mandibular furcations. J Periodontol. 1997; 68: 679-686.

[66] Zucchelli G, Cesari C, Glauser C, et al. Early bacterial accumulation on guided tissue regeneration membrane materials. An in-vivo study. J Periodontol. 1998; 69: 1193-1202.

[67] Bain CA, Moy PK. The association between the failure of dental implants and cigarette smoking. Int J Oral Maxillofac Implants. 1993; 8: 609-615.

[68] De-Bruyn H, Collaert B. The effect of smoking on early implant failure. Clin Oral Implants Res. 1994; 5: $260-264$.

[69] Bain CA. Smoking and implant failure - benefits of a smoking cessation protocol. Int J Oral Maxillofac Implants. 1996; 11: 756-759.

[70] Haas R, Haimbock W, Mailath G, et al. The relationship of smoking on peri-implant tissue: a retrospective study. J Prosthet Dent. 1996; 76: 592-596.

[71] Wilson TG Jr, Nunn M. The relationship between the interleukin-1 periodontal genotype and implant loss. Initial data. J Periodontol. 1999; 70: 724-729.

[72] Kan JY, Rungcharassaeng K, Lozada JL, et al. Effects of smoking on implant success in grafted maxillary sinuses. J Prosthet Dent. 1999; 82: 307-311.

[73] Geurs NC, Wang IC, Shulman LB, et al. Retrospective radiographic analysis of sinus graft and implant placement procedures from the Academy of Osseointegration Consensus Conference on Sinus Grafts. Int J Periodontics Restorative Dent. 2001; 21: 517-523. 
[74] M Romandini, C Lima, I Pedrinaci, et al. Prevalence and risk/protective indicators of peri-implant diseases: A university-representative cross-sectional study. Clin Oral Impl Res. 2021; 32: 112-122.

[75] Hardt CRE, Grandahl K, Lekholm U, Wennstrom JL. Outcome of implant therapy in relation to experienced loss of periodontal bone support. A retrospective 5-year study. Clin Oral Implants Res. 2002; 13: 488-494.

[76] Karoussis, IK, Salvi, GE, Heitz-Mayfield, LJA et al. Long-term implant prognosis in patients with and without a history of chronic periodontitis: a 10-year prospective cohort study of the ITI® Dental Implant System. Clin Oral Impl Res. 2003; 14: 329-339.

[77] Delatola C, Adonogianaki E, Ioannidou E. Non-surgical and supportive periodontal therapy: predictors of compliance. J Clin Periodontol. 2014; 41: 791- 796.

[78] Ramseier CA, Kobrehel S, Staub P, et al. Compliance of cigarette smokers with scheduled visits for supportive periodontal therapy. J Clin Periodontol. 2014; 41: 473- 480.

[79] Berglundh T, Armitage G, Araujo MG et al. Peri-implant diseases and conditions: Consensus report of workgroup 4 of the 2017 World Workshop on the Classification of Periodontal and Peri-Implant Diseases and Conditions. J Clin Periodontol 2018; 45 (S20): S286-S291.

[80] Georgios A, Kotsakis I, Olmedo DG. Peri-implantitis is not periodontitis: Scientific discoveries shed light on microbiome-biomaterial interactions that may determine disease phenotype. Periodontology 2000. 2021; 86: 231-240.

[81] Reitsma M, Kendrick P, Gakidou E et al. Spatial, temporal, and demographic patterns in prevalence of smoking tobacco use and attributable disease burden in 204 countries and territories, 1990-2019: A systematic analysis from the Global Burden of Disease Study 2019. 2021; 27: S0140-S0169. 